\title{
Effect of prolonged monocular deprivation (homogeneous illumination) on the CFF of the nonoccluded and occluded eye*
}

\author{
JOHN P. ZUBEK and MICHAEL BROSS \\ University of Manitoba, Winnipeg, Canada
}

\begin{abstract}
Since previous research has shown that the exposure of one eye to a prolonged period of darkness produces an initial depression followed by an enhancement of the CFF in the nonoccluded eye, an attempt was made to determine whether a similar phenomenon could be demonstrated by using diffuse, homogeneous illumination as the monocular condition. Two experiments were conducted, in which the CFFs of the nonoccluded and the occluded eyes were measured before and then at various intervals during 3 days of unpatterned visual stimulation. No significant changes in performance were observed in either eye. It was concluded that the production of this unusual interocular effect is dependent upon an absence of visual stimulation per se rather than upon an absence of pattern vision. The results were related to Sharpless's (1964) concept of "disuse of neural pathways," a revision of the law of denervation.
\end{abstract}

In a recent experiment (Zubek \& Bross, 1972), in which critical flicker fusion frequency (CFF) was determined at various intervals during $24 \mathrm{~h}$ of monocular deprivation (darkness), no significant changes in the performance of the occluded eye were observed. However, the temporal performance of the nonoccluded eye was characterized by a significant decrease in the CFF at both 3 and $6 \mathrm{~h}$, a reversal to the preexperimental baseline at $9 \mathrm{~h}$, and finally a significant increase in the CFF at the end of the 24-h period (see Fig. 2). This "depression-enhancement" (D-E) phenomenon, which was present in all of the experimental Ss, occurred regardless of whether the dominant or the nondominant (weak) eye was occluded. These results, indicating the existence of an initial depression effect, are consistent with some data obtained in two early studies. In 1923, Allen reported that $3 \mathrm{~h}$ of monocular deprivation (darkness) produced a decrease in the CFF of the nonoccluded eye, a finding subsequently confirmed by Hollenberg (1924). Furthermore, in both studies, this decreased CFF was observed on each of 15 different wavelengths, ranging from 410 to 750 millimicrons. Unfortuantely, the occluded eye was not tested, nor was a deprivation duration longer than $3 \mathrm{~h}$ employed.

Since exposing the eye to darkness involves not only an absence of visual stimulation, but also an absence of pattern vision, the question arises as to which of these two conditions is responsible for producing the D-E phenomenon in the nonoccluded eye. To provide an answer, an experiment was designed in which a white translucent patch was placed over one eye, thus producing a Ganzfeld-like condition of diffuse,

*This research was supported by the Defence Research Board. Canada (Grant 9425-08) and by the National Research Council, Canada (APA-290). The authors wish to express their appreciation to L. Bayer, D. Harper, and R. Lundin for research assistance. homogeneous illumination. If results similar to those of darkness should be obtained, an absence of pattern vision would appear to be the critical factor, while if the D-E phenomenon were not obtained, one could conclude that its occurrence was dependent upon an absence of visual stimulation per se.

\section{METHOD}

The Ss were 28 male university students, all with normal vision, who volunteered to wear a patch over one eye for a period of 3 days. They were assigned randomly to an experimental and control group, each containing 14 Ss. All Ss were paid for their participation.

Both groups of Ss were required to live for 3 days 1 in a large furnished room $(3.66 \times 14.02 \mathrm{~m})$, which contained a radio, a television set, playing cards, and reading material of their own choice (for further details of the living conditions, see Zubek \& Bross, 1972). The Ss were confined to these "apartment-like" quarters in groups of four-two experimentals and two controls. During the entire period, each experimental $S$ wore a white translucent patch over the dominant eye. ${ }^{2}$ The average illumination under the white patch, taken at sitting height in eight different positions in the room, was approximately $20 \mathrm{fc}$.

The CFF of the nonoccluded eye of the experimental Ss was determined prior to the application of the eyepatch $(0 \mathrm{~h})$ and then at intervals of $3,6,9,15,24,48$, and $72 \mathrm{~h}$ of monocular deprivation. each of the eight test periods being preceded by 15 min of binocular dark adaptation ${ }^{3}$ and a meal or a snack accompanied by a sweet chocolate bar (to control for possible effects of changes in blood sugar level on the CFF). No measurements of the occluded eye were taken. A similar procedure was applied to the confined control Ss. i.e.. the CFF of the corresponding eye (nondominant) was determined after 15 min of binocular dark adaptation at each of the eight test periods. The experiment began in the morning, the $\mathrm{Ss}$ being tested between 8:30 and 9:45 a.m. All Ss were provided with approximately $8 \mathrm{~h}$ of sleep and were awakened $1 \mathrm{~h}$ prior to the start of the 24-. 48-. and 72-h test sessions.

The stimulus consisted of a white light, at an initial flicker frequency above fusion, which was presented monocularly by a cold cathode modulating lamp mounted at the rear of a standard viewing chamber (Lafayette, Model 1202c). The angle subtended by the centrally fixated stimulus was $2 \mathrm{deg} 10 \mathrm{~min}$, a value 


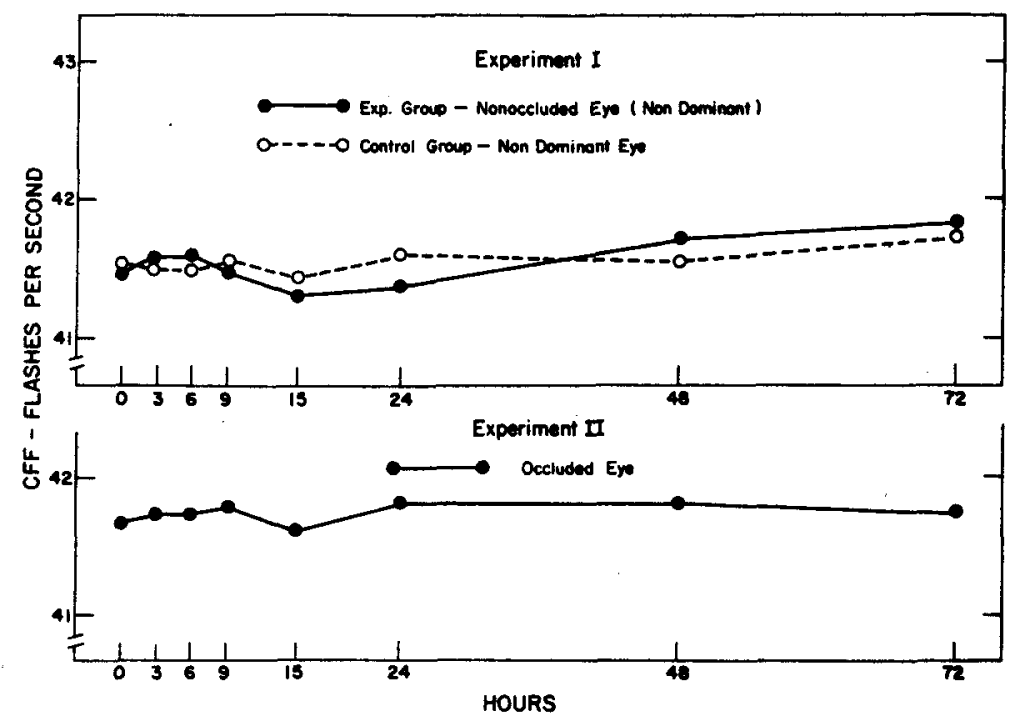

Fig. 1. (Top) Temporal changes in the mean CFF of the nonoccluded eye (nondominant) of the experimental Ss, exposed to 3 days of monocular deprivation (homogeneous illumination), relative to the changes in the nondominant eye of the confined controls. (Bottom) Temporal changes in the CFF of the occluded (dominant) eye.

assuring full foveal stimulation. The flicker-generating apparatus (Grason-Stadler, Model E622) was set at a light-dark ratio of 0.50 and a lamp current reading of $22.6 \mathrm{~mA}$. Eight trials, separated by 5 -sec intervals, were presented to the nondominant eye at each test period. The descending method of limits was used, the S's task being to report the first indication of flicker. The arithmetic mean of these eight trials was taken as the descending monocular CFF threshold.

Finally, in order to study the performance of the occluded eye which previously had not been tested, a second experiment was conducted in which the dominant eyes of eight additional Ss were covered by white patches for 3 days, the CFF being taken from the occluded eye at the same temporal intervals as before. Prior to the measurements at each of these test periods, both eyes were again dark adapted for $15 \mathrm{~min}$.

Comparability with our previous research on monocular deprivation was insured by the employment of the same research assistants, test environment, equipment, standardized test and dietary procedures, and method of recruitment of the male Ss.

\section{RESULTS}

Figure 1 (top) summarizes the results obtained from the nonoccluded eye of the experimental Ss and the corresponding eye of the confined controls. It can be seen that the CFF, in both groups of Ss, shows little or no change throughout the 3-day test period. An analysis of variance (mixed design for repeated measures, Myers, 1966) performed on this data revealed no significant between-group effects, between-duration effects, or interaction effects.

Figure 1 (bottom) summarizes the results of the second experiment. It is evident that the CFF of the occluded eye also shows little change during the 3-day period. Furthermore, the temporal performance is similar to that shown by the experimental and control Ss of the first study.

Figure 2, which is included for comparison purposes, summarizes the results of a previous study in which the dominant eye was exposed to darkness rather than homogeneous illumination (Zubek \& Bross, 1972). Note the presence of the D-E phenomenon in the nonoccluded eye (top) and its absence in the occluded eye (bottom).

\section{DISCUSSION}

The results of this study, together with those obtained

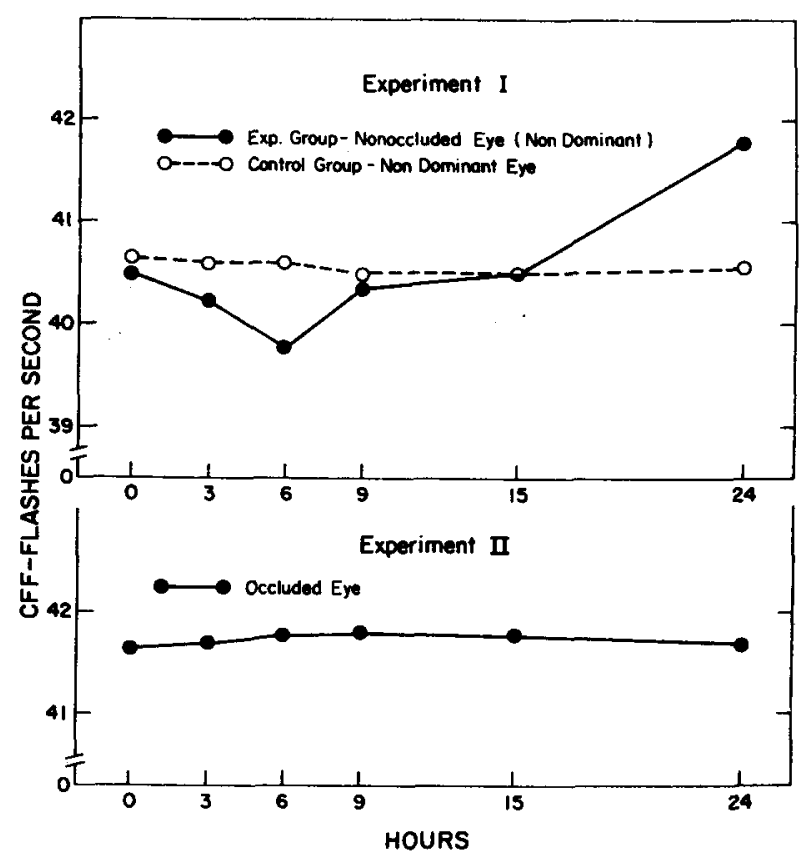

Fig. 2. (Top) Temporal changes in the mean CFF of the nonoccluded eye (nondominant) of the experimental Ss, exposed to $24 \mathrm{~h}$ of monocular deprivation (darkness), relative to the changes in the nondominant eye of the confined controls. (Bottom) Temporal changes in the CFF of the occluded (dominant) eye. (Reprinted, by permission, from J. P. Zubek and M. Bross, Science, 1972, 176, 1045-1047. Copyright 1972 by the American Association for the Advancement of Science.) 
in our earlier research, indicate that a prolonged period of monocular deprivation, consisting of either darkness or exposure to diffuse, homogeneous illumination, does not affect the CFF of the occluded eye. In contrast to this finding, these two experimental conditions appear to exert a differential effect on the performance of the nonoccluded eye. While the employment of a darkness condition has been shown to produce an initial depression (at 3 and $6 \mathrm{~h}$ ) and a subsequent enhancement of the CFF (at $24 \mathrm{~h}$ ) in the nondeprived eye, neither of these two components is present in this eye when the other eye is exposed to homogeneous illumination. Thus, it would appear that the D-E phenomenon has resulted from an absence of visual stimulation per se.

In an attempt to provide an explanation of this unusual effect, we have suggested (Bross \& Zubek, 1972; Zubek \& Bross, 1972) that it might be placed in the same category as the supersensitivity phenomena, ${ }^{4}$ which are known to occur in the higher neural centers after either drug-induced or surgically induced partial deafferentation at the lower levels of the central nervous system, a class of compensatory phenomena which Sharpless (1964), in a recent revision of the law of denervation (Cannon \& Rosenblueth, 1949; Stavraky, 1961), has stated are produced by prolonged disuse of neural pathways. Our finding that the D-E phenomenon seems to have resulted from an absence of visual stimulation per se is consistent with Sharpless's formulation. However, the question as to why this CFF effect occurs only in one eye still remains to be answered.

Finally, our demonstration that the two types of visual deprivation conditions can exert either a similar or a differential effect on performance is of general relevance to one of the controversial issues in the isolation chamber literature, namely, does the sensory deprivation techinique, employing darkness, produce the same behavioral and physiological effects as does the perceptual deprivation technique, employing unpatterned visual stimulation (see Zubek, 1969)? Although the prevalent view is that these two traditional isolation procedures yield essentially similar results, the present findings suggest that there may be exceptions.

\section{REFERENCES}

Allen, F. On reflex visual sensations. Journal of the Optical Society of America, 1923, 7, 583-626.

Bross, M., \& Zubek, J. P. Progressive increase in the CFF of the nonoccluded eye during one week of monocular deprivation. Canadian Journal of Psychology, 1972, 26, 42-53.

Cannon, W. B., \& Rosenblueth, A. The supersensitivity of denervated structures. New York: Macmillan, 1949.

Hollenberg, M. S. On the verification of the principle of reflex visual sensations. Journal of the Optical Society of America, $1924,8,713-730$.

Myers, J. L. Fundamentals of experimental design. Boston: Allyn \& Bacon, 1966.

Sharpless, S. Reorganization of function in the nervous system-use and disuse. Annual Review of Physiology, 1964, 26, 357-388.

Stavraky, G. W. Supersensitivity following lesions of the nervous system. Toronto: University of Toronto Press, 1961.

Zubek, J. P. (Ed.) Sensory deprivation: Fifteen years of research. New York: Appleton-Century-Crofts, 1969.

Zubek, J. P., \& Bross, M. Depression and later enhancement of the critical flicker frequency during prolonged monocular deprivation. Science, 1972, 176, 1045-1047.

\section{NOTES}

1. A 3-day rather than a 1-day duration of monocular deprivation was employed since it was conceivable that under a Ganzfeld-like condition, the appearance of the second component of the $\mathrm{D}-\mathrm{E}$ phenomenon might be delayed by a day or so.

2. The choice of the dominant eye for occlusion purposes was an arbitrary one, since we have already demonstrated (Zubek \& Bross, 1972) that eye dominance is not a variable in producing the D-E phenomenon.

3. The D-E phenomenon has also been demonstrated using a 30-min period of dark adaptation (Zubek \& Bross, 1972). The purpose of not using a longer duration was to avoid the risk of producing a binocular rather than a monocular deprivation condition which the bulk of the literature indicates does not affect the CFF (see Zubek, 1969).

4. These denervation supersensitivity phenomena are sometimes preceded by a period of depressed sensitivity.

(Received for publication June 1, 1972; revision received January 30,1973 .) 